\title{
Çocuklarda Ciddi Temas Yanıkları; Bir Çocuk Yanık Merkezinin 10 Yıllık
}

\section{Deneyimi}

\section{Serious Contact Burns in Children; 10 Years Experience of a Pediatric Burn Center}

\author{
Sabri DEMIR ${ }^{1,3}$ (iD Süleyman Arif BOSTANCI ${ }^{\text {(D) Elif Emel ERTEN }}{ }^{1}$ id Vildan Selin ÇAYHAN ${ }^{1}$ \\ Can İhsan öZTORUN ${ }^{2}$ (iD Metin Kaan ALTINOK ${ }^{1}$ Ahmet ERTÜRK ${ }^{1}$ (iD) DoğuşGÜNEY ${ }^{2}$ iD \\ Müjdem Nur AZILI ID Emrah ŞENEL ${ }^{2}$
}

\section{$\underline{\mathbf{o z}}$}

Amaç: Çalışmamızın amacı, çocuk yanık merkezimizde temas yanıkları nedeniyle yatırılarak tedavi ettiğimiz hastaların epidemiyolojik, karakteristik özellikleri ve uygulanan tedavi yöntemlerini değerlendirmek ve konuyla ilgili tecrübelerimizi paylaşmaktır. Araçlar ve yöntem: Hastaların dosyaları retrospektif olarak tarandı. Cinsiyet, yaş, temas şekilleri, lokalizasyonu, total yanık yüzey alanları, yanığın derinliği, yandıktan kaç gün sonra hastaneye yatırıldıkları, greft yapılıp yapılmadığı, hastanede yatış süreleri, hipertrofik skar ve eklem kontraktürleri gelişip gelişmediği kaydedildi. Ardından kız ve erkek hastalar arasında fark olup olmadığı, temas yanıklarının hangi yaş aralıklarında ve hangi aylarda daha fazla görüldüğü araştırıldı. İstatistiksel analiz SPSS version 21 paket programı ile yapıldı. Tüm değişkenler için $\mathrm{P}<0.05$ anlamlı olarak kabul edildi.

Bulgular: Toplam 29 hastanın 17'si (\%58.6) erkek ve 12'si (\%41.4) kız, ortalama yaşları 3.34 yıl, ortalama total yanık yüzey alanları $\% 4.48$, yandıktan sonra hastaneye yatırılma süreleri ortalama 6.34 gün ve hastanede yatış süreleri ortalama 13.20 gün olarak bulundu. En sık görülen temas yanı̆̆ 1 nedeni sobaya dokunma (\%51.8), en sık yanan vücut bölgesi yüz (\% 58.6) olarak tespit edildi. Eller ikinci en sık yanan (\%55.2) organlardı. Hastaların \%86.2'sı dört yaşından küçük ve çoğu evlerinde yanmışlardı.

Sonuç: Temas yanıklarının çoğu küçük çocuklarda ve evde meydana gelen önlenebilir kazalar sonucu meydana gelmektedir. Bu yanıkları önlemek için ebeveynler eğitilmeli ve alınması gereken tedbirler anlatılmalıdır. Özellikle el yanıklarında kontraktür gelişmesini önlemek için erken istirahat atelleri kullanılmalı ve erken dönemde fizik tedavi egzersizlerine başlanmalıdır.

Anahtar Kelimeler: çocuklar; greft; fleksiyon kontraktürü; hipertrofik skar; temas yanıkları

\section{ABSTRACT}

Purpose: We aimed to evaluate epidemiological, characteristic features and treatment methods of patients who have been treated in pediatric burn center due to contact burns and to share our experiences.

Materials and Methods: Files of patients were evaluated retrospectively. Gender, age, contact mechanisms, localization, total-burnedsurface areas, depth of burn, time between day-of-burn and admission to the burn center, whether grafting was made, length-of-stay in hospital, whether hypertrophic scar and contractures developed were recorded. Then, it was investigated whether there was a difference between genders, and at what age intervals and in which months contact burns were seen more frequently. Statistical analysis was done with SPSS version 21 . $\mathrm{P}<0.05$ was considered significant.

Results: Of 29 patients, 17 (58.6\%) were boys and 12 (41.4\%) were girls, their mean-age was 3.34 years, average-total-burned-surfacearea was $4.48 \%$, average day between day of the burn and admission to burn center was 6.34 , and the mean length-of-stay in hospital was 13.20 days. The most common cause was touching the stove (51.8\%), the most common burned-region was the face $(58.6 \%)$. Hands were the second most frequently burned-organs (55.2\%). Mostly patients were burnt at home and $86.2 \%$ of them were $<4$ years old.

Conclusion: Most contact burns occur in young children as a result of preventable home accidents. In order to prevent, parents should be educated and precautions to be taken should be explained. Especially in hand burns, early resting splints should be used to prevent contracture development and physical therapy exercises should be started in the early period.

Keywords: children; contact burns; flexion contracture; graft; hypertrophic scar

${ }^{3}$ Ankara Şehir Hastanesi, Cocuk Yanık Merkezi, Bilkent, Ankara, Türkiye.

Sorumlu Yazar: Uzm. Dr. Sabri DEMİ, Ankara Şehir Hastanesi, Çocuk Cerrahisi Kliniği, Bilkent, Ankara, Türkiye. e-posta: drsabridemir@gmail.com 


\section{GíRiş}

Yanık travmaya bağlı ölümlerin en önemli nedenlerdendir. ${ }^{1}$ Beş yaşın altındaki çocuklarda en sık haşlanma yanıkları görülür (\%60-70) ve bunu sırasıyla temas yanıkları $(\% 20)$, alev yanıkları (\%15) ve diğer yanık nedenleri (\%5) takip eder. ${ }^{2}$ Ancak 5-18 yaş aralığındaki çocuklarda alev yanıkları (\%45) daha sık görülürler. Bunu sırasıyla haşlanma yanıkları (\%33), temas yanıkları (\%10) ve diğer yanık nedenleri (\%12) takip ederler. ${ }^{3}$ İki yaşından küçük küçük çocuklarda ise yanıkların \%7-30'unu temas yanıkları oluşturmaktadır., ${ }^{4,5}$ Özellikle 1sıtma aracı olarak kullanıldığı evlerde sobaya dokunma, temas yanıklarının en sık nedenidir.

Çocuklarda görülen temas yanıkları genelde önlenebilir ev kazaları nedeni ile olur ve bu olgular genellikle üç yaşından küçük çocuklardır. ${ }^{6}$ Bu çocuklarda en çok el avuçlarının yandığ 1 bildirilmiştir. ${ }^{6}$ Temas yanıkları genelde derin yanıklar şeklinde görülürler. ${ }^{7}$

Çalışmamızın amacı, son 10 yıl içinde çocuk yanık merkezimizde temas yanıkları nedeniyle tedavi ettiğimiz hastaların epidemiyoloji, karakteristikleri ve uygulanan tedavi yöntemlerini değerlendirmek ve konuyla ilgili tecrübelerimizi paylaşmaktır.

\section{ARAÇLAR ve YÖNTEM}

Çalışma retrospektif olarak planlandı. Gerekli etik kurul izni Ankara Şehir Hastanesi 2 Nolu Klinik Araştırmalar etik kurulundan (Karar No: E2-21-179, Tarih: 24.02.2021) alındı. Çocuk yanık merkezimizde 01.01.2010 ve 31.12.2020 tarihleri arasında yatırılıp tedavi edilen tüm hastaların fiziki ve elektronik ortamdaki dosyaları retrospektif olarak tarandi. Bu hastalardan temas yanıkları nedeniyle yatırılan, yaşları 0-18 yıl arasında olan hastalar değerlendirmeye alındı. 18 yaşından büyük ve temas yanığı dışındaki nedenlerle yatırılan hastalar değerlendirmeye alınmadi.

Önce çalışma için bir excel dosyası oluşturuldu. Bu dosyaya, hastaların cinsiyet, yaş, temas şekilleri, lokalizasyonu, total yanık yüzey alanları, yanığın derinliği, yandıktan kaç gün sonra hastaneye yatırıldıkları, greft yapılıp ya- pılmadığı, hastanede yatış süreleri, hipertrofik skar ve eklemlerinde fleksiyon kontraktürleri gelişip gelişmediği kaydedildi. Ardından hastalar cinsiyetlerine göre kız ve erkek olarak ikiye ayrıldı. Gruplar arasında farklılık olup olmadığı araştırıldı. Daha sonra hastalar yaşlarına göre 0-4, 5-13 ve 14-18 yaş şeklinde üç gruba ayrılarak hangi yaş aralıklarında daha fazla temas yanıklarının görüldüğü araştırıldı. En sonunda da hastalar yandıkları aylara göre sınıflandırılıp temas yanıklarının aylar ile ilişkisi araştırild1.

\section{İstatistiksel Analiz}

İstatistiksel analiz the Statistical Package for Social Sciences (SPSS) software version 21 (SPSS Inc., Chicago, IL, USA) paket programı ile yapıldı. Nümerik değişkenler olan hastaların yaşları, total yanık yüzey alanları, yandıktan kaç gün sonra hastaneye yatırıldıkları ve yatış süreleri ortalama \pm std.dev (min-max) olarak ile ifade edildi. Cinsiyet, temas şekilleri, lokalizasyonu, derinliği, greft yapılıp yapılmadığı, yanık alanında skar veya kontraktür gelişip gelişmediği gibi kategorik değişkenler ise görülme sıklıkları (frekans) ve yüzdeleri ile ifade edildi. Kız ve erkek grupları arasındaki farklılıklar nümerik değişkenler normal dağılmadıkları ve sayıları az oldukları için Mann-Whitney U testi kullanılarak, kategorik değişkenler ise Fischer's Exact ve Chi-Square testleri ile çapraz tablo analizleri yapılarak araştırıldı. Tüm değişkenler için $\mathrm{p}<0.05$ anlamlı olarak kabul edildi.

\section{BULGULAR}

Çocuk yanık merkezimizde 01.01.2010 ve 31.12.2020 tarihleri arasında toplam 29 hasta temas yanığı tanısı ile yatırılarak tedavi edildi. Bunlardan 17'si (\%58.6) erkek idi. Hastaların yaş ortalaması $3.34 \pm 4.42$ yıl (0.1-16.24), ortalama total yanık yüzey alanları \% $4.48 \pm 4.96$ (1-21) olarak bulundu. En sık görülen temas yanığı şekli soba ile temas idi ( $\mathrm{n}=15 ; \% 51.8)$. En küçük hastamız 50 günlük bir kız çocuğu idi ve bezinin içine konan sıcak kum ile temas neticesinde yanık meydana gelmişti. Bir hastada trafik kazası esnasında aniden açılan hava yastığının hızla sürtünmesi ile, bir hasta ise yerde bulunan sıcak davul fırının üzerine düşme sonucu yanmıştı. Diğer hastaların temas şekilleri şekil 1. de detaylı olarak gösterilmiştir. 


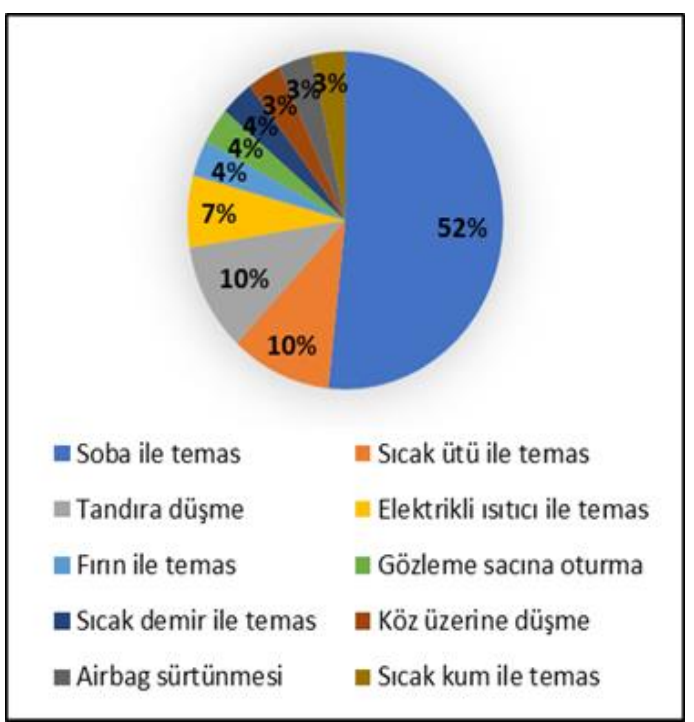

Şekil 1. Hastaların temas yanıklarının meydana geliş şekilleri

Hastaların en sık yanan vücut bölgesi yüzleri olurken, bunu ikinci sırada el yanıkları takip etmekteydi. Yedi hastada (\%24.1) sadece yüz ve 10 hastada (\%34.5) eller ile birlikte olmak üzere toplam 17 hastada (\%58.6) yüz yanığı vardı. Hastaların yanan vücut bölgeleri şekil 2. de detaylı olarak verilmiştir.

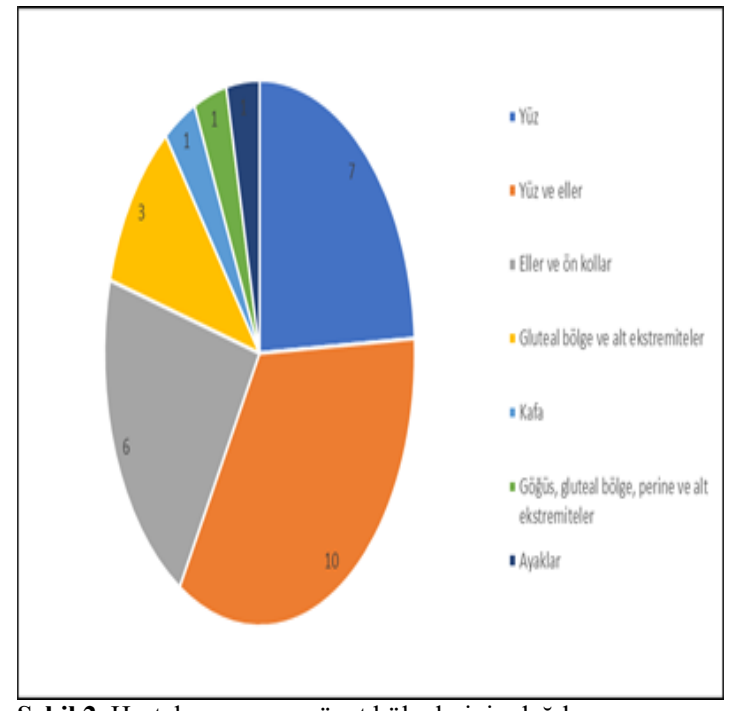

Şekil 2. Hastaların yanan vücut bölgelerinin dağılımı

Yedi hastada (\%24.1) üçüncü derece, 22 hastada (\%75.9) ise ikinci derece yanık meydana gelmişti. İkinci derece yanıkları olan 22 hastadan onikisinin (\%41.4) yanıkları yüzeyel, on kişinin (\%34.5) ise derin ikinci derece yanıklardı. Oniki hastaya (\%41.4) greft yapıldı. On beş hastada (\%51.7) yanık alanında hipertrofik skar gelişti. Hiçbir hastada ampütasyon ihtiyacı olmadı. Temas yanıkları nedeniyle hayatını kaybeden hastamız olmadı.
Hastaların demografik verileri Tablo 1. de detaylı olarak gösterilmiştir.

Tablo 1. Hastaların demografik verileri

\begin{tabular}{ll}
\hline & Sonuç, n(\%) \\
\hline Cinsiyet & $17(58.6)$ \\
Erkek & $12(41.4)$ \\
Kız & $3.34 \pm 4.42$ \\
& $(0.14-16.24)$ \\
Yaş, Ortalama \pm Std. Dev. (Min-Max) & \\
& $4.48 \pm 4.96$ \\
Total Yanık Yüzey Alanı (\%), & $(1.0-21.0)$ \\
Ortalama \pm Std. Dev. (Min-Max) & \\
& $6.34 \pm 17.0$ \\
Yanıktan sonra kaçıncı günde yatırıldığı, & $(0.0-90.0)$ \\
Ortalama \pm Std. Dev. (Min-Max) & \\
& $13.20 \pm 15.15$ \\
Ortalama yatış süresi (gün), & $(1.0-61.0)$ \\
Ortalama \pm Std. Dev. (Min-Max) & $\mathrm{n}(\%)$ \\
Yanık Derinliği & $12(41.4)$ \\
İkinci derece yüzeyel yanık & $10(34.5)$ \\
İkinci derece derin yanık & $7(24.1)$ \\
Üçüncü derece yanık & $12(41.4)$ \\
Greft yapılan, n(\%) & $15(51.7)$ \\
Hipertrofik skar gelişen, n(\%) & \\
\hline & \\
&
\end{tabular}

Cinsiyetlerine göre hastalar karşılaştırıldığında kız ve erkek hastalar arasında yaş, toplam yanık yüzey alanları, yandıktan sonra kaçıncı günlerde yatırıldıkları, hastaneden yatış süreleri, temas şekli, yanığın lokalizasyonu, derinliği açılarından istatistiksel olarak fark bulunmadı. Tüm gruplarda $\mathrm{P}>0.05$ idi. Erkek çocuklarında greft yapılma oranları daha fazla olmasına rağmen (\%58.8' e karşın \%25) her iki cinsiyet arasında istatistiksel olarak fark bulunmadı $(\mathrm{P}>0.05)$. Sadece kız çocuklarında yanık alanlarında yara iyileştikten sonra daha fazla hipertrofik skar geliştiği görüldü $(\mathrm{P}=0.047)$. Her iki cinsiyete ait verilerin istatistiksel analizi Tablo 2. de detaylı olarak verilmiştir.

Yirmibeş hastanın (\%86.2) yaşı dört yaşın altındaydı. Temas yanıkları en çok yaşları 12-24 ay arasında bulunan çocuklarda meydana gelmişti. Sadece üç çocuk (\%10.3) 14 yaşından büyüktü. 
Tablo 2. Hastaların cinsiyetlerine göre verilerinin istatistiksel analizi

\begin{tabular}{|c|c|c|c|}
\hline Değișken & $\operatorname{Kuz}(n=12)$ & $\begin{array}{l}\text { Erkek } \\
(n=17)\end{array}$ & $\mathbf{p}$ \\
\hline $\begin{array}{l}\text { Yaş, Ortalama } \pm \\
\text { Std. Dev. (Min-Max) }\end{array}$ & $\begin{array}{l}3.05 \pm 3.8 \\
(0.14-14.75)\end{array}$ & $\begin{array}{l}3.5 \pm 4.8 \\
(0.25-16.24)\end{array}$ & $0.790^{*}$ \\
\hline $\begin{array}{l}\text { Toplam Yanık Yüzey Alanı } \\
\text { (\%), Ort.土 } \\
\text { Std. Dev. (Min-Max) }\end{array}$ & $\begin{array}{l}5.5 \pm 6.1 \\
(1.0-21.0)\end{array}$ & $\begin{array}{l}3.8 \pm 3.9 \\
(1.0-15.0)\end{array}$ & $0.455^{*}$ \\
\hline $\begin{array}{l}\text { Yandıktan sonra kaçıncı } \\
\text { günde yatırıldığı, } \\
\text { Ort. } \pm \text { Std. Dev. (Min-Max) }\end{array}$ & $\begin{array}{l}1.4 \pm 2.8 \\
(0-10.0)\end{array}$ & $\begin{array}{l}9.8 \pm 21.7 \\
(0-90.0)\end{array}$ & $0.225^{*}$ \\
\hline $\begin{array}{l}\text { Yatış Süresi (gün), Ort. } \pm \\
\text { Std. Dev. (Min-Max) }\end{array}$ & $\begin{array}{l}14.03 \pm 19.4 \\
(1.0-61.0)\end{array}$ & $\begin{array}{l}12.58 \pm 11.8 \\
(1.0-45.0)\end{array}$ & $0.424^{*}$ \\
\hline \multicolumn{4}{|l|}{ Temas şekli, n(\%) ** } \\
\hline Soba ile temas & $6(\% 50.0)$ & $9(52.9)$ & $0.466^{* * *}$ \\
\hline Sicak ütü ile temas & 0 & $3(17.6)$ & \\
\hline Tandıra düşme & $2(16.7)$ & $1(5.9)$ & \\
\hline Elektrikli isitıcı ile temas & $1(8.3)$ & $1(5.9)$ & \\
\hline Firın ile temas & $1(8.3)$ & 0 & \\
\hline Gözleme sacına oturma & 0 & $1(5.9)$ & \\
\hline Sicak demir ile temas & 0 & $1(5.9)$ & \\
\hline Köz üzerine düşme & 0 & $1(5.9)$ & \\
\hline Airbag sürtünmesi & $1(8.3)$ & 0 & \\
\hline Sicak kum ile temas & $1(8.3)$ & 0 & \\
\hline \multicolumn{4}{|l|}{ Lokalizasyon, $\mathbf{n}(\%) * *$} \\
\hline Yüz & $3(25.0)$ & $4(23.5)$ & $0.442^{* * *}$ \\
\hline Yüz ve eller & $5(41.7)$ & $5(29.4)$ & \\
\hline Eller ve ön kol & $1(8.3)$ & $5(29.4)$ & \\
\hline $\begin{array}{l}\text { Gluteal bölge ve } \\
\text { alt ekstremiteler }\end{array}$ & $2(16.7)$ & $1(5.9)$ & \\
\hline Kafa & 0 & $1(5.9)$ & \\
\hline $\begin{array}{l}\text { Göğüs, gluteal bölge, } \\
\text { perine ve } \\
\text { alt ekstremiteler }\end{array}$ & $1(8.3)$ & 0 & \\
\hline Ayaklar & 0 & $1(5.9)$ & \\
\hline \multicolumn{4}{|l|}{ Yanık Derinliği, n(\%) } \\
\hline İkinci derece yüzeyel yanık & $7(58.3)$ & $5(29.5)$ & $0.139^{* * *}$ \\
\hline İkinci derece derin yanık & $3(25.0)$ & $9(52.9)$ & \\
\hline Üçüncü derece yanık & $2(16.7)$ & $3(17.6)$ & \\
\hline \multicolumn{4}{|l|}{ Greft durumu, n(\%) } \\
\hline Yapilan & $3(25.0)$ & $10(58.8)$ & $0.071^{* * * * *}$ \\
\hline Yapilmayan & $9(75.0)$ & $7(41.2$ & \\
\hline \multicolumn{4}{|l|}{ Hipertrofik skar, n(\%) } \\
\hline Gelişen & $4(33.3)$ & $12(70.6)$ & $0.047^{* * * *}$ \\
\hline Gelişmeyen & $8(66.7)$ & $5(29.4)$ & \\
\hline
\end{tabular}

* M ann - Whit ney U testi ile analiz yapıld 1 .

** Değeri "0" olan gruplar en yakın grup ile birleştirilerek karşılaştırma yapild1.

*** Fischer's Exact testi ile analiz yapıld1.

**** Pearson Chi-Square testi ile analiz yapıldı.

Temas yanıklarının havaların soğumaya başladığg Eylül ayından itibaren artmaya başladığı ve kış aylarında daha fazla görüldüğü tespit edildi. Buna göre en çok vaka Kasım ( $\mathrm{n}=6)$ ayında görüldü. Temas yanıklarının aylara göre dağılımı şekil 3. de verilmiştir.

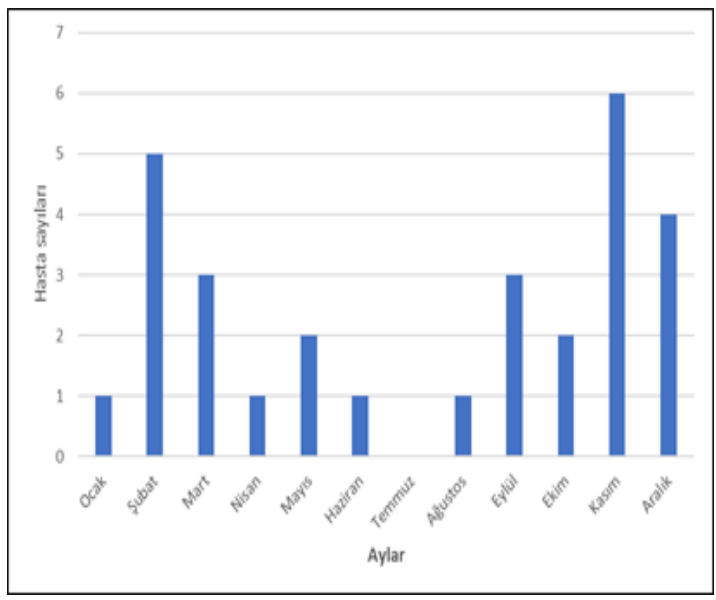

Şekil 3. Temas yanıklarının aylara göre dağılımı

\section{TARTIŞMA}

Temas yanığı tanısı ile tedavi edilen olgularımızın büyük kısmı (\%86.2) dört yaş altındaydı. Bu olgular ev ortamında meydana gelen önlenebilir ev kazaları sonucunda yanmışlard1. En sık yanan vücut bölgeleri yüzleri, bunu ikinci s1rada elleri takip etmekteydi. En sık temas edilen eşya soba ve en sık temas yanığı kış aylarında meydana gelmişti.

Çocuklarda görülen temas yanıklarının çoğu önlenebilir ev kazaları şeklinde görülürler. Bu tür yanıklar, genelde evde bulunan soba, sıcak ütü, elektrikli 1sıtıcı, fırın kapağı gibi sıcak bir objeye dokunma sonucunda meydana gelirler. ${ }^{8}$ Dünya genelinde de temas yanıkları en sık soba ile temas sonucu oluşur. Örneğin, McBride ve arkadaşları Amerika Birleşik Devletlerinde, ülkemize benzer şekilde çocuklarda temas yanıklarının en sık soba ile temas sonucu meydana geldiğini bildirmişlerdir. ${ }^{9} \mathrm{Xu}$ ve arkadaşları da Çin'de temas yanıklarının en sık soba ile temas sonucu meydana geldiğini bildirmişlerdir. ${ }^{10}$ Bizim hastalarımızda da en çok görülen yanma şekli soba ile temas şeklinde olup literatür ile uyumlu idi. Soba yerine başka ısıtma araçlarının kullanıldığı ülkelerde ise en sık bu eşyalara dokunarak temas yanıkları oluşur. Örneğin, Zettel ve arkadaşları Kanada'da çocuklarda görülen temas yanıklarının çoğunun evlerde kullanılan şöminelere temas sonucu meydana geldiğini bildirmişlerdir. ${ }^{11}$ Grossova ve arkadaşları da Bulgaristan'da çocuklarda temas yanıklarının en sık şömineye dokunma sonucu meydana geldiğini bildirmişlerdir. ${ }^{12}$ Javaid ve arkadaşları ise 806 çocuk hastayı içeren serilerinde temas yanıklarının en çok sıcak firın kapağı ile temas sonucu meydana geldiğini bildirmişlerdir. ${ }^{6}$ Ülkemizde, özellikle kırsal kesimlerde soba hala evlerin çoğunda ısıtma 
aracı olarak kullanılmaktadır. Çocukların sobalara erişimini kısıtlayan basit bariyer sistemleri bulunmaktadır. Küçük yaşlarda çocukları olan ebeveynlere bu sistemleri kullanmaları önerilerek soba ile temas yanıkları büyük oranda önlenebilir.

Soba ile temas sonucu meydana gelen temas yanıklarının mevsimsel özellik taşıdığı ve özellikle havaların soğuk olduğu kış aylarında daha fazla meydana geldiği gözlenmiştir. Xu ve arkadaşları da en sık temas yanıklarının kış ayları olan Aralık, Ocak ve Şubat aylarında meydana geldiğini bildirmiştir. ${ }^{10}$ Bununla ilgili sonuçlarımızda literatür ile uyumlu idi.

Emekleyen ve yürümeye yeni başlayan çocuklar etraflarındaki eşyaları tanımak için her yere elleriyle dokunurlar. Bu yüzden de sıcak cisimlere dokunmayla temas yanıkları ellerde sık meydan gelmektedir. Literatürde, temas yanıklarında çocuklarda en sık el ve parmakların yandığı bildirilmiştir. ${ }^{9,11}$ Ancak bizim hastalarımızda en sık yanan vücut bölgesinin tek başına veya ellerle birlikte yüz olduğu görüldü. Yüz yanıklarını ikinci sırada el yanıkları takip etmekteydi. Bu hususta sonuçlarımız literatür ile uyumlu değildi. Bu sonuç, yürümeye yeni başlayan çocukların yürürken dengelerini kaybedip soba veya diğer sıcak objelerin üzerine yüzlerinin üstüne devrilerek yanmalarına bağlandi.

Diğer travmalar gibi yanık ta erkek çocuklarda daha fazla görülür. ${ }^{13} \mathrm{Bu}$, erkek çocukların daha hareketli olmasına bağlanır. Ancak temas yanıkları küçük çocuklarda daha fazla görüldüğü için her iki cinsiyet arasında genelde fark bulunmaz. ${ }^{6}$ Dört yaşın altındaki hastalarımızda her iki cinsiyet arasında istatistiksel fark bulunmamasına rağmen, dört yaşın üzerinde bulunan dört hastadan üç'ü erkek biri kız idi.

Temas yanıkları genelde derin yanıklardır. Bunun sonucunda da greft yapılma oranları yüksektir. Ayrıca, bu hastaların parmak eklemlerinde yüksek oranda fleksiyon kontraktürleri geliştiği de bilinmektedir. ${ }^{14}$ Hastalarımızın \%41.4'üne greft yapıldı ve yarıdan fazlasında hipertrofik skar geliştiği görüldü. El yanıkları olan ve düzenli kontrole gelen sekiz hastanın parmak eklemlerinde fleksiyon kontraktürleri gelişti. Bu hastaların hepsine fizik tedavi egzer- siz tedavisi ve rekonstrüktif operasyonlar yapıldı. Bu nedenle, özellikle eklemlerinde yanıkları olan hastaların erken dönemde fizik tedavi egzersizlerine başlamaları önem arz etmektedir. Ek olarak, bu hastalarda tedavilerinin bir parçası olarak, yanmış elleri erken dönemde istirahat atellerine alınarak takip edilmelidir.

Tandır yanıkları ülkemizin Doğu ve Güneydoğu illerinde daha fazla görülmektedir. ${ }^{15} \mathrm{Bu}$ yanıklarda morbidite ve mortalite diğer temas yanıklarından daha yüksektir. ${ }^{16}$ Üç hastamız tandıra düşerek yanmıştı. Bu hastalar, yanma sürecini tamamlamış olan ve köz haline gelmiş ateşin üzerine düşerek temas sonucu meydana geldiği ve elbiselerinde de temas noktalarından başka alev yanığı görülmediği için temas yanığı olarak değerlendirildi. Her üç hasta da Doğu ve Güneydoğu bölgelerinden sevk edilmişti. Bu hastaların yanık yüzey alanları diğer temas yanıklarına göre daha büyük ve daha derin idi. Ekmek pişirilirken çocukların uzaklaştırılması veya tandırların ağızlarının daraltılması gibi tedbirler alınarak tandır yanıklarının önüne geçilebilir.

Her retrospektif çalışma gibi çalışmamızın da bazı kısıtlılıkları bulunmaktadır. Bunlardan ilki tek merkezli bir çalışma olmasıdır. Merkezimiz üçüncü basamak bir çocuk yanık merkezi olduğu için hafif yanıkların çoğu periferde bulunan yanık ünitelerinde tedavi edilmektedir. $\mathrm{Bu}$ nedenle hafif olgularında tedavi edildiği üniteleri de içeren çok merkezli çalışmalar epidemiyolojik açıdan daha gerçekçi sonuçlar verecektir. Çalışmamızın bir diğer kısıtlılığı da sadece çocuk yanık merkezinde yatırılıp tedavi edilen hastaların çalışmaya dahil edilmesidir. Ancak yanık hastalarının çocuk cerrahisi ve yanık polikliniklerinin yanı sıra acil servislere de başvurmaları ve kayıt sistemlerinin sağlıklı olmaması nedeniyle sadece yanık merkezine yatırilan hastalar dahil edildi.

Sonuç olarak, temas yanıkları çocuklarda diğer yanık etkenlerine oranla daha az görülmelerine rağmen daha yüksek morbiditeye sahiptirler. Bu yanıkların çoğu dört yaşından küçük çocuklarda ve ev içinde meydana gelen önlenebilir kazalar sonucunda meydana gelmektedir. Çoğu soba ile temas sonucu meydana geldiği için çocukların sobalara direkt temasını engelleyen özel yapılmış bariyer sistemleri kullanılarak soba ile temas yanıkları önlenebilir. Bu yanıkların önlenmesinde anne-babaların eğitimi ve bilinçlendirilmesi kritik öneme haizdir. Bunun için yazıll, görsel ve 
sosyal medya aracılığı ile ebeveynlere sürekli eğitimler verilmeli ve bu kazaların önlenmesi için alınması gereken tedbirler anlatılmalıdır. Özellikle el yanıklarında fleksiyon kontraktürleri sık gelişir. Bunun gelişmesini önlemek için eklemleri içine alan temas yanıklarında hemen istirahat atelleri kullanılmalı ve erken dönemde fizik tedavi egzersizlerine başlanmalıdır. Gerektiği zaman gecikmeden rekonstrüktif cerrahiler yapılmalıdır.

\section{Çıkar Beyannamesi}

Yazarlar, herhangi bir çıkar çatışmasının olmadığını beyan etmektedirler.

\section{Araştırmacıların Katkı Oranı Beyanı}

Ana fikir/Planlama: SD, EŞ. Veri toplama/İşleme: SD, VSÇ, MKA. Veri analizi ve yorumlama: SD, SAB, CïÖ. Literatür taraması: SD, AE, EEE, DG, MNA. Yazım: SD, EŞ. Gözden geçirme ve düzeltme: SD, EŞ. Danışmanlık: EŞ.

\section{KAYNAKÇA}

1. Oztorun CI, Demir S, Azili MN, Senayli A, Livanelioglu Z, Senel E. The outcomes of becoming a pediatric burn center in Turkey. Ulus Travma Acil Cerrahi Derg. 2016;22(1):34-39.

2. Nunez LO, Norbury WB, Herndon DN, Lee JO. Special Considerations of Age: The Pediatric Burned Patient. Herndon DN ed. Total Burn Care. 5th ed. Elsevier; 2018:372-380.e372.
3. Wolf SE, Cancio LC, Pruitt BA. Epidemiological, Demographic and Outcome Characteristics of Burns. Herndon DN ed. Total Burn Care. 5th ed. Elsevier; 2018:14-27.e12

4. Kemp AM, Jones S, Lawson Z, Maguire SA. Patterns of burns and scalds in children. Arch Dis Child. 2014;99(4):316-321.

5. Lee W, Cho KR, Lee JH. Contact burn due to a heatedwire breathing circuit. J Anesth. 2014;28(5):802.

6. Javaid AA, Bennett V, Hollen L, Kemp AM. Contact burns: the influence of agents and mechanisms of injury on anatomical burn locations in children $<5$ years old and associations with child protection referrals. Arch Dis Child. 2020;105(6):580-586.

7. Argirova M, Hadzhiyski O. Treatment of palm burns in children. Ann Burns Fire Disasters. 2005;18(4):190193

8. Hakan Çinal EZB. Five Years of Experience In A Burn Care Unit: Analysis Of Burn Injuries In 667 Patients. Van Med. J. 2020;27(1):56-62.

9. McBride JM, Romanowski KS, Sen S, Palmieri TL, Greenhalgh DG. Contact Hand Burns in Children: Still a Major Prevention Need. J Burn Care Res. 2020;41(5):1000-1003.

10. $\mathrm{Xu} \mathrm{JH,} \mathrm{Qiu} \mathrm{J,} \mathrm{Zhou} \mathrm{JH,} \mathrm{et} \mathrm{al.} \mathrm{Pediatric} \mathrm{burns} \mathrm{in} \mathrm{mili-}$ tary hospitals of China from 2001 to 2007: a retrospective study. Burns. 2014;40(8):1780-1788.

11. Zettel JC, Khambalia A, Barden W, Murthy T, Macarthur C. Gas fireplace contact burns in young children. J Burn Care Rehabil. 2004;25(6):510-512.

12. Grossova I, Zajicek R, Kubok R, Smula MC. The treatment of palmar contact burns in children: a five-year review. Ann Burns Fire Disasters. 2017;30(1):5-8.

13. Toon MH, Maybauer DM, Arceneaux LL, et al. Children with burn injuries--assessment of trauma, neglect, violence and abuse. J Inj Violence Res. 2011;3(2):98110 .

14. Pham TN, Hanley C, Palmieri T, Greenhalgh DG. Results of early excision and full-thickness grafting of deep palm burns in children. J Burn Care Rehabil. 2001;22(1):54-57.

15. Al B, Coban S, Guloglu C. Tandir burns in and around Diyarbakir, Turkey. Ulus Travma Acil Cerrahi Derg. 2010;16(1):59-62.

16. Akcay MN, Ozturk G, Aydinli B, Ozogul B. Tandir burns: a severe cause of burns in rural Turkey. Burns. 2008;34(2):268-270 